Review Article

\title{
Reciprocal regulation between alternative splicing and the DNA damage response
}

Adrian E. Cambindo Botto ${ }^{1}$, Juan C. Muñoz ${ }^{1}$, Luciana E. Giono ${ }^{1}$, Nicolás Nieto-Moreno ${ }^{1}$, Carmen Cuenca ${ }^{1}$, Alberto R. Kornblihtt ${ }^{1}$ and Manuel J. Muñoz ${ }^{1,2,3}$ (iD

${ }^{1}$ Universidad de Buenos Aires, Facultad de Ciencias Exactas y Naturales, Departamento de Fisiologia, Biologia Molecular y Celular, Instituto de Fisiologia, Biologia Molecular y Neurociencias

(IFIBYNE-UBA-CONICET), Buenos Aires, Argentina.

${ }^{2}$ Fondazione Istituto FIRC di Oncologia Molecolare (IFOM), Milan, Italy.

${ }^{3}$ Universidad de Buenos Aires, Facultad de Ciencias Exactas y Naturales, Departamento de Biodiversidad y

Biología Experimental, Buenos Aires, Argentina.

\begin{abstract}
Splicing, the process that catalyzes intron removal and flanking exon ligation, can occur in different ways (alternative splicing) in immature RNAs transcribed from a single gene. In order to adapt to a particular context, cells modulate not only the quantity but also the quality (alternative isoforms) of their transcriptome. Since $95 \%$ of the human coding genome is subjected to alternative splicing regulation, it is expected that many cellular pathways are modulated by alternative splicing, as is the case for the DNA damage response. Moreover, recent evidence demonstrates that upon a genotoxic insult, classical DNA damage response kinases such as ATM, ATR and DNA-PK orchestrate the gene expression response therefore modulating alternative splicing which, in a reciprocal way, shapes the response to a damaging agent.

Keywords: DNA damage, alternative splicing, ATR, ATM, DNA-PK.
\end{abstract}

Received: April 04, 2019; Accepted: December 16, 2019.

\section{Introduction}

A human gene is a DNA sequence that codes for a molecule with a certain function. The diversity of these molecules, including RNAs or proteins, outnumbers human genes, thereby demonstrating that amplification mechanisms of DNA information necessarily take place. The vast majority of human genes have exonic sequences (Lander et al., 2001; Venter et al., 2001) that are normally included in the mature RNA molecule and introns, sequences that are present in the immature RNA, or pre-RNA, but are absent in the mature RNA. Splicing, the process that catalyzes intron removal and flanking exons ligation, can occur in different ways (alternative splicing) in pre-RNAs transcribed from the same gene, thereby increasing the number of possible mature RNAs that can be obtained from a single gene. Alternative splicing (AS) is the most common mechanism that amplifies DNA encoded information since it occurs in more than the $95 \%$ of the human genes (Barash et

Send correspondence to Manuel J. Muñoz. Instituto de Fisiologia, Biologia Molecular y Neurociencias (IFIBYNE-UBA-CONICET), Facultad de Ciencias Exactas y Naturales, Universidad de Buenos Aires, Ciudad Universitaria, C1428EHA Buenos Aires, Argentina. E-mail: mmunoz@fbmc.fcen.uba.ar, manuel.munoz@ifom.eu al., 2010). Genes involved in the DNA damage response (DDR) are not the exception, and many genes associated to cell cycle control, DNA repair, or controlled cell death are regulated by AS (Giono et al., 2016). Regulation of gene expression by AS can modify the balance between, for instance, pro- and anti-apoptotic factors. As an example, the exclusion of an alternative sequence in the Bcl-x mRNA results in a shorter protein that acts as a dominant negative, competing with the full-length protein that has a role in promoting apoptosis (Muñoz et al., 2009). Nevertheless, there exists a reciprocal regulation between AS and the DDR, since it has been recently demonstrated that classical factors involved in the DDR such as ATM (ataxia telangiectasia mutated), ATR (ataxia telangiectasia mutated and Rad3 related), and DNA-PK have a paramount role in gene expression and AS regulation in a genotoxic scenario.

\section{Alternative splicing regulation}

Splicing, and therefore AS, is mainly a co-transcriptional process (Kotovic et al., 2003; Lacadie and Rosbash, 2005; Listerman et al., 2006; Pandya-Jones and Black, 2009; Ameur et al., 2011; Tilgner et al., 2012) and, as such, is regulated not only by factors that bind to the pre-RNA but also by the transcription process itself (Kornblihtt et al., 
2013). In other words, transcription and splicing are coupled processes that therefore can regulate each other. Nowadays there is a big corpus of data on the functional coupling between transcription and splicing, but one of the most clear pieces of evidence still comes from one of the first reports: more than twenty years ago the Kornblihtt group showed that alternative exon inclusion is greatly affected by promoter identity. To demonstrate this, mammalian cells were transfected with plasmids containing a given RNAPII promoter and an alternative exon surrounded by constitutive exons, a so called AS reporter minigene. The only difference between these minigenes was the promoter, each of them giving place to identical pre-RNA molecules. After total RNA purification, retro-transcription and PCR amplification of AS isoforms, it was observed that the ratio of exon inclusion/skipping was drastically affected by promoter identity, demonstrating an intimate connection between transcription and pre-RNA processing (Cramer et al., 1997). Moreover, transcription by an RNAPII lacking its carboxy-terminal domain (CTD), a repetitive structure rich in amino acids subject to post-translational modifications (Corden et al., 1985), also affects AS regulation (de la Mata and Kornblihtt, 2006; Muñoz et al., 2010). In fact, mutations in the CTD sequence that prevent or mimic its phosphorylation, by replacing serines with alanines or glutamic acids respectively, also modulate AS patterns (Muñoz et al., 2009). These results demonstrate that, although the catalytic activity of RNAPII is not located in the CTD, the phosphorylation state of this domain is crucial for pre-RNA processing. Moreover, the role of transcription in the control of AS was further confirmed by the finding that transcription factors (Kadener et al., 2001; Nogues et al., 2002), coactivators (Auboeuf et al., 2004), transcription enhancers (Kadener et al., 2002), as well as chromatin remodelers (Batsche et al., 2006) and factors that alter chromatin structure (Schor et al., 2009; Luco et al., 2010; Saint-Andre et al., 2011), modulate AS. Coupling of transcription and AS most likely occurs through different factors interacting with a particular state of post-translational modification of the CTD. Then, the transcriptional complex can, in turn, either directly affect splice site selection or the speed (i.e., elongation rate) of the polymerase. According to the kinetic coupling model, a slow elongation rate of the transcribing RNAPII favors co-transcriptional recognition of a weak splice site, or other significant sequence in the pre-mRNA, before a stronger site located downstream is synthesized (Kornblihtt et al., 2013). We have shown that UV exposure induces the hyperphosphorylation of the CTD, which reduces RNAPII elongation rates, thus affecting splice site selection of several genes, some of which are key for survival/apoptosis decisions (Muñoz et al., 2009).

\section{Regulation of alternative splicing in a genotoxic scenario}

Exposure to regular DNA damaging agents such as UV radiation, chemicals, or oxidative stress may affect every human gene. As an example, treating cells in culture with $20 \mathrm{~J} / \mathrm{m}^{2}$ of UV light $(254 \mathrm{~nm}$ ) induces 4 photoproducts every $10 \mathrm{kbp}$, enough to damage every single one of the 21,000 human genes (van Hoffen et al., 1995). In any case, upon exposure to UV radiation, some of these genes are less expressed, other genes are more expressed, and a bigger group remains unaffected (Muñoz et al., 2017). Although it is clear that DNA damage in cis affects gene expression by at least altering the pace of a single transcribing RNAPII molecule in a damaged template (Geijer and Marteijn, 2018), in trans signaling does also take place and, therefore, we should pay attention to the different molecular mechanisms activated by DNA damage in order to understand how gene expression is regulated.

The fact that UV light affects AS in trans was demonstrated by at least two simple experiments. Firstly, transfection of pre-irradiated cells with an AS reporter minigene elicited similar AS patterns as those obtained when irradiating cells after transfection, demonstrating that UV light can control AS in trans (Muñoz et al., 2009). Secondly, transfection of an in vitro UV-irradiated plasmid, with no transcriptional units or relevant sequences for mammalian cells, mimicked the AS patterns of UV-treated cells in AS reporter minigenes, therefore showing again, but by other means, that UV-induced DNA damage in cis is not necessary to induce the UV effect on AS (Muñoz et al., 2017). Therefore, UV light, and in particular UV-induced DNA damage, affects gene expression in trans.

In the past few years we learned a simple lesson when studying gene expression control in a genotoxic scenario: there may be new functions for old players. While members of class-IV phosphoinositide 3-kinase (PI3K)-related kinase (PIKK) family, such as Ataxia-Telangiectasia-Mutated (ATM), Ataxia Telangiectasia and Rad3-related (ATR), and DNA-dependent Protein Kinase (DNA-PK), have well established roles in the response to different types of DNA damage (Awasthi et al., 2015), novel roles in the control of gene expression under stress where recently described (Tresini et al., 2015; Muñoz et al., 2017; Liu et al., 2019). Below, we will briefly discuss recent evidence showing the contribution of these DDR kinases to gene expression regulation.

The involvement of ATR in the control of AS upon UV irradiation was demonstrated by our group using human keratinocytes, the most abundant cell type in the skin. Nucleotide Excision Repair (NER) is one of the most versatile DNA repair systems in human cells, dealing with lesions induced by UV light, chemicals and some forms of oxidative damage (Nouspikel, 2009). We found that single stranded DNA (ssDNA) exposed during NER-dependent repair of UV-induced cyclobutane pyrimidine dimers 
(CPDs) activates the ATR kinase, which indirectly affects the phosphorylation state of RNAPII's CTD (Muñoz et al., 2017). The UV effect is enhanced by inhibition of gapfilling DNA synthesis, the last step in NER, supporting the notion of a role for ssDNA in the activation of an ATRdependent signaling cascade controlling CTD phosphorylation and gene expression. Global Genome NER (GGNER) is the branch of NER active throughout the whole genome and not just in transcriptionally active genes, as is the case for Transcription Coupled NER (TC-NER). As the UV effect on gene expression was reduced in the absence of DDB2/XPE, the main GG-NER sensor of CPDs, we proposed that less recognition would generate less ssDNA intermediates and consequently a decreased UV effect on gene expression (Muñoz et al., 2017; Cambindo Botto et al., 2018).

On the other hand, the role of ATM in the control of gene expression has been reported using human fibroblasts (Tresini et al., 2015). They showed that a transcriptionblocking DNA lesion induces spliceosome displacement from the nascent pre-RNA, therefore increasing R-loop formation which, in turn, activates ATM. According to the authors, activation of ATM further regulates spliceosome displacement, thus affecting gene expression globally (Tresini et al., 2015).

Finally, a role for DNA-PK in the control of AS was recently suggested upon double strand break (DSB) induction. DSBs are repaired throughout the cell cycle by the non-homologous end joining (NHEJ) pathway, in which DNA-PK has a paramount role. The authors found that DNA-PK co-localizes with nuclear speckles, dynamic nuclear structures enriched in splicing factors, and its inactivation affected a set of AS events (Liu et al., 2019).

\section{Alternative splicing regulation of DDR}

As mentioned earlier, AS affects the expression of nearly the entire genome, and factors involved in every aspect of the DDR are not the exception. Members of the p53, Mdm, bcl-2, or caspase families of genes, among many others, are modulated by AS, affecting key aspects of the encoded products, such as their activity, localization, or halflife (Giono et al., 2016). Consequently, DNA repair, the control of cell cycle, or the induction of cell death are key mechanisms regulated by AS and, not surprisingly, their misregulation can drive to cellular transformation (Shkreta and Chabot, 2015). The best-documented examples are Bcl-x (Muñoz et al., 2009) and Caspase 9 (Shultz et al., 2010), whose AS variants can promote or inhibit the apoptotic pathway. Although in the vast majority of cases the functional impact of the different AS isoforms is missing, evidence showing how AS regulates different aspects of the DDR accumulates. For instance, it has been shown recently that PRMT5, an arginine methyl transferase, controls AS patterns of the homologous recombination (HR) factor Tip60 altering the balance between HR and non- homologous end joining (NHEJ) (Hamard et al., 2018), and that SIRT1, a NAD-dependent protein deacetylase, regulates AS patterns of different DDR factors (Wang et al., 2018). Also, different splicing variants of BRCA1, a well know cancer susceptibility gene, modulate DNA repair mechanisms (Sevcik et al., 2013), and the BRCA1 protein has been shown to be a regulator of the splicing process, affecting the expression of repair factors (Savage and Harkin, 2015). Moreover, as it has been documented in other reviews (Shkreta and Chabot, 2015), mRNA isoforms of the cell cycle CDC25B phosphatase (Baldin et al., 1997) and the DDR kinase CHK2 (Berge et al., 2010) display dominant-negative effects.

Finally, having in mind that transcription promotes not only opening of the DNA double helix and exposure of ssDNA, but also changes in DNA supercoiling, nucleosome occupancy, and collisions with replisomes in S phase (Bermejo et al., 2011), it is not surprising that the transcriptional process by itself acts as a DNA damaging agent. The fact that highly expressed genes show high levels of mutagenesis is one of the many hints demonstrating that transcription affects the integrity of DNA (Kim et al., 2007; Svejstrup, 2010). Therefore transcription, an essential process for life, also acts as a DNA damaging agent. While it is clear that transcription regulates alternative splicing, it is also clear that alternative splicing regulates transcription. In an elegant study, the Svejstrup laboratory recently showed that transcription, and therefore the genome's damage load, is regulated by alternative splicing, since the ASCC3 gene generates isoforms that are able to favor (ASCC3 short isoform), or inhibit (long isoform) transcription recovery after DNA damage (Williamson et al., 2017). Upon UV irradiation, general transcription is shut down (Rockx et al., 2000), and RNAPII elongation rate decreases (Muñoz et al., 2009), favoring the expression of shorter alternative splicing variants (Williamson et al., 2017). After some time, during which DNA damage load partially decreases due to repair, transcriptional re-start is favored, since low elongation rates favor the expression of the ASCC3 short isoform. A possible interpretation is that in a DNA damage scenario global transcription should be shut down. This is not to prevent mRNA mutations, but to avoid transcription-associated damage in an already damaged DNA.

\section{Concluding remarks}

Since AS is modulated by DNA damage and, in turn, modulates the response to a genotoxic agent (Figure 1), it is of interest to specifically manipulate AS patterns of key genes that may offer a benefit from a clinical point of view. As with the successful therapies using modified oligonucleotides to prevent the usage of a splice site in the treatment of spinal muscular atrophy (Wang et al., 2018), the challenge is to identify specific AS isoforms whose expres- 


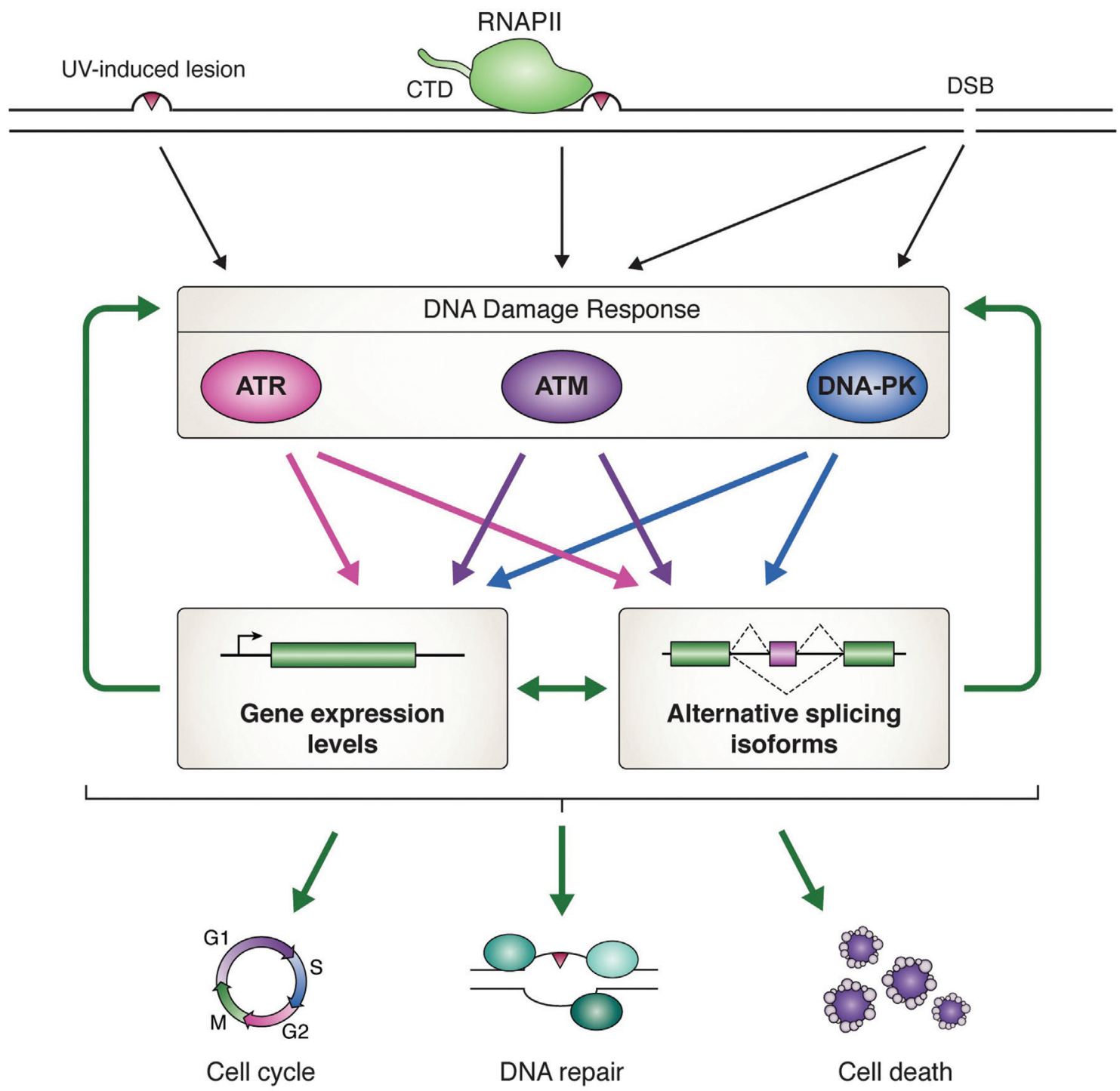

Figure 1 - Roles recently reported for the kinases ATR, ATM and DNA-PK are depicted. UV-induced DNA lesions activate ATR and ATM, the latter being activated in particular by stalling of transcribing RNAPII. Double strand breaks (DSB) activate ATM and DNA-PK. These three central DDR kinases modulate gene expression globally, both by regulating gene expression levels and by modifying AS patterns. This modulation, in turn, tunes the DDR by modulating cell-cycle regulation, DNA repair and cell death.

sion may help to prevent cellular transformation or enhance cell death.

\section{Acknowledgments}

We thank all the members of the Muñoz and Kornblihtt groups, as well as members of the Srebrow, Schor, de la Mata and Petrillo labs. This work was supported by grants from the Agencia Nacional de Promoción Científica y Tecnológica of Argentina to ARK (PICT-2014-2582, PICT-2015-0341) and MJM (PICT 2017-0046). MJM, ARK and LEG are career investigators of and AECB, JCM and NNM received fellowships from the Consejo Nacional de Investigaciones Científicas y Técnicas of Argentina (CONICET).

\section{Conflict of Interest}

The authors declare that they have no conflicts of interest with the contents of this article.

\section{Author Contributions}

MJM wrote the manuscript. AECB, JCM, LEG, NNM, CC and ARK corrected the manuscript. LEG produced the figure all authors read and approved the final version.

\section{References}

Ameur A, Zaghlool A, Halvardson J, Wetterbom A, Gyllensten U, Cavelier L and Feuk L (2011) Total RNA sequencing reveals nascent transcription and widespread co-transcriptio- 
nal splicing in the human brain. Nat Struct Mol Biol 18:1435-1440.

Auboeuf D, Dowhan DH, Kang K, Larkin K, Lee JW, Berget SM and O'Malley BW (2004) Differential recruitment of nuclear receptor coactivators may determine alternative RNA splice site choice in target genes. Proc Natl Acad Sci U S A 101:2270-2274.

Awasthi P, Foiani M and Kumar A (2015) ATM and ATR signaling at a glance. J Cell Sci 128:4255-4262.

Baldin V, Cans C, Knibiehler M and Ducommun B (1997) Phosphorylation of human CDC25B phosphatase by CDK1-cyclin A triggers its proteasome-dependent degradation. J Biol Chem 272:32731-3274.

Barash Y, Calarco JA, Gao W, Pan Q, Wang X, Shai O, Blencowe BJ and Frey BJ (2010) Deciphering the splicing code. Nature 465:53-59.

Batsche E, Yaniv M and Muchardt C (2006) The human $\mathrm{SWI} / \mathrm{SNF}$ subunit Brm is a regulator of alternative splicing. Nat Struct Mol Biol 13:22-29.

Berge EO, Staalesen V, Straume AH, Lillehaug JR and Lonning PE (2010) Chk2 splice variants express a dominant-negative effect on the wild-type Chk2 kinase activit. Biochim Biophys Acta 1803:386-395.

Bermejo R, Capra T, Jossen R, Colosio A, Frattini C, Carotenuto W, Cocito A, Doksani Y, Klein H, Gómez-González B et al. (2011) The replication checkpoint protects fork stability by releasing transcribed genes from nuclear pores. Cell 146:233-246.

Cambindo Botto AE, Munoz JC and Munoz MJ (2018) Coupling between nucleotide excision repair and gene expression. RNA Biol 15:845-848.

Corden JL, Cadena DL, Ahearn JM Jr and Dahmus ME (1985) A unique structure at the carboxyl terminus of the largest subunit of eukaryotic RNA polymerase II. Proc Natl Acad Sci U S A 82:7934-7938.

Cramer P, Pesce CG, Baralle FE and Kornblihtt AR (1997) Functional association between promoter structure and transcript alternative splicing. Proc Natl Acad Sci U S A 94:1145611460.

de la Mata M and Kornblihtt AR (2006) RNA polymerase II C-terminal domain mediates regulation of alternative splicing by SRp20. Nat Struct Mol Biol 13:973-980.

Geijer ME and Marteijn JA (2018) What happens at the lesion does not stay at the lesion: Transcription-coupled nucleotide excision repair and the effects of DNA damage on transcription in cis and trans. DNA Repair (Amst) 71:56-68.

Giono LE, Nieto Moreno N, Cambindo Botto AE, Dujardin G, Munoz MJ and Kornblihtt AR (2016) The RNA response to DNA damage. J Mol Biol 428:2636-2651.

Hamard PJ, Santiago GE, Liu F, Karl DL, Martinez C, Man N, Mookhtiar AK, Duffort S, Greenblatt S, Verdun RE et al. (2018) PRMT5 Rregulates DNA repair by controlling the alternative splicing of histone-modifying enzymes. Cell Rep 24:2643-2657.

Kadener S, Cramer P, Nogues G, Cazalla D, de la Mata M, Fededa JP, Werbajh SE, Srebrow A and Kornblihtt AR (2001) Antagonistic effects of T-Ag and VP16 reveal a role for RNA pol II elongation on alternative splicing. EMBO J 20:57595768.

Kadener S, Fededa JP, Rosbash M and Kornblihtt AR (2002) Regulation of alternative splicing by a transcriptional enhancer through RNA pol II elongation. Proc Natl Acad Sci U S A 99: 8185-8190.

Kim N, Abdulovic AL, Gealy R, Lippert MJ and Jinks-Robertson S (2007) Transcription-associated mutagenesis in yeast is directly proportional to the level of gene expression and influenced by the direction of DNA replication. DNA Repair (Amst) 6:1285-1296.

Kornblihtt AR, Schor IE, Allo M, Dujardin G, Petrillo E and Munoz MJ (2013) Alternative splicing: A pivotal step between eukaryotic transcription and translation. Nat Rev Mol Cell Biol 14:153-165.

Kotovic KM, Lockshon D, Boric L and Neugebauer KM (2003) Cotranscriptional recruitment of the U1 snRNP to introncontaining genes in yeast. Mol Cell Biol 23:5768-5779.

Lacadie SA and Rosbash M (2005) Cotranscriptional spliceosome assembly dynamics and the role of U1 snRNA:5'ss base pairing in yeast. Mol Cell 19:65-75.

Lander ES, Linton LM, Birren B, Nusbaum C, Zody MC, Baldwin J, Devon K, Dewar K, Doyle M, FitzHugh W et al. (2001) Initial sequencing and analysis of the human genome. Nature 409:860-921.

Listerman I, Sapra AK and Neugebauer KM (2006) Cotranscriptional coupling of splicing factor recruitment and precursor messenger RNA splicing in mammalian cells. Nat Struct Mol Biol 13:815-822.

Liu S, Shao Y, Wang Q, Zhai Y and Li X (2019) Genotoxic stress causes the accumulation of DNA-dependent protein kinase catalytic subunit phosphorylated at serine 2056 at nuclear speckles and alters pre-mRNA alternative splicing. FEBS Open Bio 9:304-314.

Luco RF, Pan Q, Tominaga K, Blencowe BJ, Pereira-Smith OM and Misteli T (2010) Regulation of alternative splicing by histone modifications. Science 327:996-1000.

Muñoz MJ, Pérez Santangelo MS, Paronetto MP, de la Mata M, Pelisch F, Boireau S, Glover-Cutter K, Ben-Dov C, Blaustein M, Lozano JJ et al. (2009) DNA damage regulates alternative splicing through inhibition of RNA polymerase II elongation. Cell, 137:708-720.

Muñoz MJ, de la Mata M and Kornblihtt AR (2010) The carboxy terminal domain of RNA polymerase II and alternative splicing. Trends Biochem Sci 35:497-504.

Muñoz MJ, Nieto Moreno N, Giono LE, Cambindo Botto AE, Dujardin G, Bastianello G, Lavore S, Torres-Mendez A, Menck CFM, Blencowe BJ et al. (2017) Major roles for pyrimidine dimers, nucleotide excision repair, and ATR in the alternative splicing response to UV irradiation. Cell Rep 18:2868-2879.

Nogues G, Kadener S, Cramer P, Bentley D and Kornblihtt AR (2002) Transcriptional activators differ in their abilities to control alternative splicing. J Biol Chem 277:43110-43114.

Nouspikel T (2009) DNA repair in mammalian cells : Nucleotide excision repair: variations on versatility. Cell Mol Life Sci 66:994-1009.

Pandya-Jones A and Black DL (2009) Co-transcriptional splicing of constitutive and alternative exons. RNA 15:1896-1908.

Rockx DA, Mason R, van Hoffen A, Barton MC, Citterio E, Bregman DB, van Zeeland AA, Vrieling $\mathrm{H}$ and Mullenders LH (2000) UV-induced inhibition of transcription involves repression of transcription initiation and phosphorylation of RNA polymerase II. Proc Natl Acad Sci U S A 97:1050310508. 
Saint-Andre V, Batsche E, Rachez C and Muchardt C (2011) Histone $\mathrm{H} 3$ lysine 9 trimethylation and HP1 gamma favor inclusion of alternative exons. Nat Struct Mol Biol 18:337344.

Savage KI and Harkin DP (2015) BRCA1, a 'complex' protein involved in the maintenance of genomic stability. FEBS J 282:630-646.

Schor IE, Rascovan N, Pelisch F, Allo M and Kornblihtt AR (2009) Neuronal cell depolarization induces intragenic chromatin modifications affecting NCAM alternative splicing. Proc Natl Acad Sci U S A 106:4325-4330.

Sevcik J, Falk M, Macurek L, Kleiblova P, Lhota F, Hojny J, Stefancikova L, Janatova M, Bartek J, Stribrna J et al. (2013) Expression of human BRCA1Delta17-19 alternative splicing variant with a truncated BRCT domain in $\mathrm{MCF}-7$ cells results in impaired assembly of DNA repair complexes and aberrant DNA damage response. Cell Signal 25:11861193.

Shkreta L and Chabot B (2015) The RNA splicing response to DNA damage. Biomolecules 5:2935-2977.

Shultz JC, Goehe RW, Wijesinghe DS, Murudkar C, Hawkins AJ, Shay JW, Minna JD and Chalfant CE (2010) Alternative splicing of caspase 9 is modulated by the phosphoinositide 3-kinase/Akt pathway via phosphorylation of SRp30a. Cancer Res 70:9185-9196.

Svejstrup JQ (2010) The interface between transcription and mechanisms maintaining genome integrity. Trends Biochem Sci 35:333-338.

Tilgner H, Knowles DG, Johnson R, Davis CA, Chakrabortty S, Djebali S, Curado J, Snyder M, Gingeras TR and Guigo R (2012) Deep sequencing of subcellular RNA fractions shows splicing to be predominantly co-transcriptional in the human genome but inefficient for lncRNAs. Genome Res 22:1616-1625.

Tresini M, Warmerdam DO, Kolovos P, Snijder L, Vrouwe MG, Demmers JA, van IJcken WF, Grosveld FG, Medema RH, Hoeijmakers JH et al. (2015) The core spliceosome as target and effector of non-canonical ATM signalling. Nature 523:53-58.

van Hoffen A, Venema J, Meschini R, van Zeeland AA and Mullenders LH (1995) Transcription-coupled repair removes both cyclobutane pyrimidine dimers and 6-4 photoproducts with equal efficiency and in a sequential way from transcribed DNA in xeroderma pigmentosum group $\mathrm{C}$ fibroblasts. EMBO J 14:360-367.

Venter JC, Adams MD, Myers EW, Li PW, Mural RJ, Sutton GG, Smith HO, Yandell M, Evans CA, Holt RA et al. (2001) The sequence of the human genome. Science 291:1304-1351.

Wang G, Wang F, Ren J, Qiu Y, Zhang W, Gao S, Yang D, Wang Z, Liang A, Gao Z et al. (2018) SIRT1 involved in the regulation of alternative splicing affects the DNA damage response in neural stem cells. Cell Physiol Biochem 48:657669.

Williamson L, Saponaro M, Boeing S, East P, Mitter R, Kantidakis T, Kelly GP, Lobley A, Walker J, Spencer-Dene B et al. (2017) UV irradiation induces a non-coding RNA that functionally proposes the protein encoded by the same gene. Cell 168:843-855.

Associate Editor: Luís Mariano Polo

License information: This is an open-access article distributed under the terms of the Creative Commons Attribution License (type CC-BY), which permits unrestricted use, distribution and reproduction in any medium, provided the original article is properly cited. 